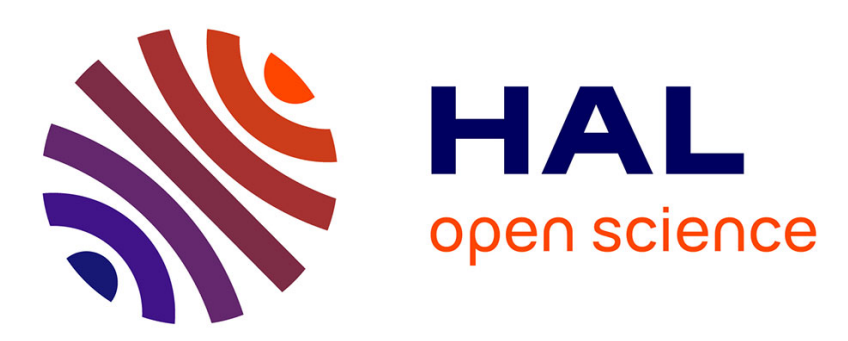

\title{
The left inferior frontal gyrus under focus: an fMRI study of the production of deixis via syntactic extraction and prosodic focus
}

Hélène Loevenbruck, Monica Baciu, Christoph Segebarth, Christian Abry

\section{- To cite this version:}

Hélène Loevenbruck, Monica Baciu, Christoph Segebarth, Christian Abry. The left inferior frontal gyrus under focus: an fMRI study of the production of deixis via syntactic extraction and prosodic focus: An fMRI study of the production of deixis. Journal of Neurolinguistics, 2005, 18, pp.237-258. 10.1016/j.jneuroling.2004.12.002 . hal-00371865

\section{HAL Id: hal-00371865 https://hal.science/hal-00371865}

Submitted on 30 Mar 2009

HAL is a multi-disciplinary open access archive for the deposit and dissemination of scientific research documents, whether they are published or not. The documents may come from teaching and research institutions in France or abroad, or from public or private research centers.
L'archive ouverte pluridisciplinaire HAL, est destinée au dépôt et à la diffusion de documents scientifiques de niveau recherche, publiés ou non, émanant des établissements d'enseignement et de recherche français ou étrangers, des laboratoires publics ou privés. 
THE LEFT INFERIOR FRONTAL GYRUS UNDER FOCUS:

AN FMRI STUDY OF THE PRODUCTION OF DEIXIS VIA

SYNTACTIC EXTRACTION AND PROSODIC FOCUS

\author{
Hélène Lœvenbruck ${ }^{\mathrm{a}^{*}}$, Monica Baciu ${ }^{\mathrm{b}}$, Christoph Segebarth $^{\mathrm{c}}$, Christian $^{-}$ \\ Abry $^{\mathrm{a}}$
}

anstitut de la Communication Parlée, UMR CNRS 5009 / INPG / Université Stendhal, 46 av. Félix Viallet, 38031 Grenoble Cedex 01, France,

${ }^{\mathbf{b}}$ Laboratoire de Psychologie et Neurocognition / UMR CNRS 5105, Université Pierre Mendès-France, BP 47, 38040 Grenoble Cedex 09, France,

${ }^{c}$ Unité Mixte INSERM / Université Joseph Fourier, U594 Neuroimagerie Fonctionnelle et Métabolique, LRC CEA 30V, Centre Hospitalier Universitaire, Pavillon B, BP 217, 38043 Grenoble Cedex 09, France.

Running title:

An fMRI study of the production of deixis

* Corresponding author:

Tel: + 33476574714

Fax: + 33476574710

e-mail: loeven@icp.inpg.fr 


\begin{abstract}
The left inferior frontal gyrus (LIFG, BA 44, 45, 47) has been associated with linguistic processing (from sentence- to syllable- parsing) as well as action analysis. We hypothesize that the function of the LIFG may be the monitoring of action, a function well adapted to agent deixis (verbal pointing at the agent of an action). The aim of this fMRI study was therefore to test the hypothesis that the LIFG is involved during the production of agent deixis.

We performed an experiment whereby three kinds of deictic sentences were pronounced, involving prosodic focus, syntactic extraction and prosodic focus with syntactic extraction.

A common pattern of activation was found for the three deixis conditions in the LIFG (BA 45 and/or 47), the left insula and the bilateral premotor (BA 6) cortex. Prosodic deixis additionally activated the left anterior cingulate gyrus (BA 24, 32), the left supramarginal gyrus (LSMG, BA 40) and Wernicke's area (BA 22).

Our results suggest that the LIFG is involved during agent deixis, through either prosody or syntax, and that the LSMG and Wernicke's area are additionally required in prosody-driven deixis. Once grammaticalized, deixis would be handled solely by the LIFG, without the LSMG and Wernicke's area.
\end{abstract}

\title{
KEYWORDS
}

Speech production, prosodic focus, syntactic extraction, agent deixis, Left Inferior Frontal Gyrus. 


\section{INTRODUCTION}

The left inferior frontal gyrus (LIFG; Brodmann Areas (BA) 44, 45 and 47) has been the focus of numerous studies in different fields, ranging from neuropsychology to formal linguistics. Various interpretations as to the roles of the LIFG have thus arisen.

Broca's original hypothesis that the LIFG must be dedicated to the production of fluent, articulate speech (Broca, 1861) has been reconsidered in the 1960s when it was noticed that Broca's aphasics, in addition to having problems with speech production, also present difficulties in speech comprehension (Caramazza \& Zurif, 1976). This observation has led the LIFG to be considered as the locus for syntax - both in speech production and in speech comprehension (Zurif, 1980). Broca's aphasics may remain capable of some syntactic processing, however, and they may fail only for specific syntactic constructions (such as for object cleft sentences, center-embedded relatives or for passive constructions; see for instance Grodzinsky, Piñango, Zurif \& Drai, 1999 for a review). It was therefore concluded that the LIFG could not be considered as the locus for all aspects of syntax (Linebarger, Schwartz \& Saffran, 1983).

Various functional roles have been assigned to the LIFG since then, on the basis of neuroimaging data and further observations on Broca's aphasics. Grodzinsky (Grodzinsky, 2000) has argued that the LIFG must have a highly restricted role, handling intrasentential dependency relations only (tracking of moved phrasal constituents in grammatical decoding and building of full-fledged syntactic trees in grammatical encoding). Other, less specific, roles in syntactic processing have been assigned to the LIFG. For instance, it has been considered to be involved in complex syntactic processing when thematic-role monitoring is required, i.e. the processing of “who-does-what-to-whom" (Just, Carpenter, Keller, Eddy \& Thulborn, 1996; Caplan, 
Alpert, Waters \& Olivieri, 2000). In agreement with this analysis, Friederici hypothesizes that the LIFG must be associated with the procedural syntactic knowledge, which depends on temporal parameters and on sequencing (Friederici, 1990; see also Friederici, 2002). This hypothesis is in line with the results from studies on sequence processing. LIFG activation has been observed during phoneme detection requiring sequence processing (Démonet, Price, Wise \& Frackowiak, 1994). Certain data suggest that the LIFG is also involved in the processing of non-linguistic sequences (Penhune, Zatorre \& Evans, 1998; Dominey \& Lelekov, 2000), while other data, such as those on procedural learning in Broca's aphasia, seem to support the hypothesis of a linguistic specificity of the LIFG (Goschke, Friederici, Kotz \& van Kampen, 2001).

The involvement of the LIFG in complex syntactic processing has been questioned by Stowe and colleagues (Stowe, Broere, Paans, Wijers, Mulder, Vaalburg et al., 1998, Stowe, 2000; see also Hickok, 2000) who attribute the LIFG activations associated with sentential complexity to processes in working memory. They argue that the LIFG only supports temporary storage of verbal information (including information on the phrasal syntactic and semantic structure) during sentence processing.

In an a priori unrelated domain, the LIFG has been associated with the observation and mental imagery of actions such as object grasping (Grafton, Arbib, Fadiga \& Rizzolatti, 1996) or finger motion (Iacoboni, Woods, Brass, Bekkering, Mazziotta \& Rizzolatti, 1999; Binkofski, Amunts, Stephan, Posse, Schormann, Freund, et al., 2000). Rizzolatti, Fogassi \&Gallese (1997) have suggested that the LIFG must be linking recognition of motor action (understanding actions performed by others) and production of motor action, a prerequisite in the phylogenetic development of communication and speech. Grèzes \& Decety (2001) argue however that some tasks having been considered to activate the LIFG (such as implicit motor imagery, complex 
manipulation of objects) seem rather to involve the premotor cortex. Also, Grèzes and colleagues (Grèzes, Costes \& Decety, 1998) were unable to replicate Rizzolatti et al.'s activation of the LIFG during "observation-in-order-to-imitate", while they obtained its involvement during the observation of meaningful actions. They therefore conclude that the activations of the LIFG must rather reflect silent verbalization, and that the LIFG must be associated solely with speech processing. However, Buccino, Binkofski, Fink, Fadiga, Fogassi, Gallese et al. (2001) observed a somatotopic organization of the activations in the premotor cortex (including the LIFG) during the observation of motor actions performed with different effectors. The LIFG was activated during the observation of mouth and hand actions but not during the observation of foot actions. These results are not in line with the verbalization hypothesis, which entails that the LIFG should be activated during observation of the action, whatever the effector used.

On the basis of this abundant literature, we hypothesize that the role of the LIFG is that of an attentional parser of action, which is well adapted to linguistic processing. This action parser supports the attentional monitoring of thematic roles handled in morphosyntactic analysis and is involved in the spatial and temporal indexing of predicates (actions) and their arguments (patient, agent). If the LIFG is involved in linguistic action parsing, then deixis on the agent of an action - in the sense of verbal pointing at the agent (Levinson, 1983) - which requires thematic-role monitoring, should activate the LIFG. The aim of the present fMRI study was therefore to explore the cerebral activations due to the production of deictic sentences. Three types of deictic sentences were tested, involving agent deixis through either prosody or syntax, or through a combination of both ${ }^{\mathrm{i}}$. 


\section{MATERIALS AND METHODS}

\section{Subjects}

Sixteen healthy, male, right-handed (Edinburgh Handedness Inventory, Oldfield, 1971) native speakers of French were examined. All subjects gave their informed consent for the fMRI examination. The study was performed in accordance with the institutional review board regulations.

\section{Stimuli}

The stimuli consisted of short sentences in French, visually presented in the middle of a projection screen. The following four isosyllabic sentences were presented, one for each condition:

(1) Baseline condition:

"Madeleine m'amena"

(/ma.də.len.ma.mə.na/, Madeleine brought me around),

(2) Prosodic deixis condition:

"MADELEINE m'amena"

(MADELEINE brought me around),

(3) Syntactic deixis condition:

“C'est Mad'leine qui m'am'na"

(/sc.ma.dlen.ki.ma.mna/, It's Mad'leine who brought me 'round),

(4) Combined deixis condition (prosodic and syntactic deixis):

“C'est MAD'LEINE qui m'am'na”

(It's MAD'LEINE who brought me 'round).

When the first name "Madeleine" was presented in capital letters, the subjects were instructed to use contrastive focus, as if they were correcting a wrong information 
communicated to them, such as: "Jennifer brought you around" (rather than Madeleine). In addition, it was made clear to the subjects that, when they were requested to produce the syntactic extraction construction, the latter was meant to point at the agent "Madeleine", excluding all other possible agents (such as "Jennifer").

The number of syllables in the sentence was maintained equal to 6 , using schwa deletion. Each sentence was presented for 3 seconds at the beginning of the corresponding condition. Then a fixation mark, alternating every 3 seconds between a '+' and a ' $x$ ' sign, appeared in the middle of the screen. This alternation was aimed at triggering the silent repetition (14 times per condition) of the sentence presented. The stimuli were generated by means of Psyscope V.1.1 (Carnegie Mellon Department of Psychology) running on a Macintosh computer (Power Macintosh 9600). They were transmitted to the subjects by means of a video projector (Eiki LC 6000), a projection screen situated behind the magnet and a mirror centered above the subject's eyes.

\section{Paradigm and tasks}

A day before the experiment, the subjects were extensively trained with the 4 sentences listed above (over and over rehearsal of the 4 conditions). The subjects were positioned in front of a computer screen, instructed and trained to execute the tasks, first in an overt speech production mode, then in a covert mode.

Pre- and post-scan audio DAT recordings were carried out to estimate the subjects' task performance during the fMRI scan. Subjects were prompted by exactly the same script as during the scans. They produced each of the sentences 4 times (instead of 14 times per condition in the actual experiment). For the pre-scan recording, they were instructed to speak aloud, at a comfortable speaking rate. For the post-scan recording, the instruction was to speak aloud and to produce the same intonation patterns they had mentally produced during the scans. 
Pre- and post-scan acoustic recordings were assessed using the Praat software (Boersma, 2001). Duration and fundamental frequency (F0) measurements were semiautomatically carried out on each of the 256 utterances (16 subjects, 4 repetitions of each of the 4 conditions). For the duration analysis, the beginning and end of each utterance were detected from the spectrogram using classical phonetic criteria (onset of voicing for $/ \mathrm{ma} /$, onset of noise for $/ \mathrm{s} \varepsilon /$, offset of voicing for $/ \mathrm{na} /$ ). For the intonation analysis, peak F0 values were automatically measured using a peak-detection algorithm on the F0 traces provided by the Praat software.

Three functional scans were performed during each fMRI session. A block paradigm was used. A scan comprised eight epochs (each condition was repeated once) of 42 seconds each. The order of presentation of the four conditions was alternated between scans and between subjects. Subjects were instructed to silently read the sentence presented at the beginning of each condition and to repeat it, using inner speech, at each alternation of the fixation cross. Thus, during each epoch, the specific sentence was repeated 14 times.

\section{MR acquisition}

Functional MR imaging was performed on a 1.5 Tesla MR imager (Philips NT) with echo-planar (EPI) acquisition. Twenty-five adjacent, axial, slices (5 mm thickness each) were imaged 10 times during each epoch. The imaging volume was oriented parallel to the bi-commissural plane. It thus encompassed the whole brain and the upper part of the cerebellum. It was measured several times in a dummy fashion before presentation of the stimuli, so that system stability could be achieved. Positioning of the image planes was performed on scout images acquired in the sagittal plane. An EPI MR pulse sequence was used for the functional scans. The major MR parameters of this 
sequence were: $\mathrm{TR}=3700 \mathrm{~ms}, \mathrm{TE}=45 \mathrm{~ms}$, pulse angle $=90^{\circ}$, acquisition matrix $=$ $64 \times 64$, reconstruction matrix $=128 \times 128$, field-of-view $=256 \times 256 \mathrm{~mm}^{2}$. Between the first and the second functional MR scans, a high-resolution 3D anatomical MR scan was obtained from the volume functionally examined.

\section{Data processing}

Data analysis was performed using the SPM-99 software (Wellcome Department of Cognitive Neurology, London, UK) running on a Unix workstation under the MATLAB environment (Mathworks, Sherbon, USA).

Functional MR images were subjected to the following pre-processing steps. In a first step, motion correction was applied. All images within a functional scan were realigned by means of a rigid body transformation. Then, the anatomical volume was spatially normalized into a reference space using as template a representative brain from the Montreal Neurological Institute series. The normalization parameters were subsequently applied to the set of functional images. Finally, to conform to the assumption underlying SPM that the data are normally distributed, and to allow for some inter-subject variability during group analysis, the functional images were spatially smoothed.

\section{Statistics}

Contrasts between conditions were determined pixelwise using the General Linear Model. Statistical significance threshold for individual pixels was established at $\mathrm{p}=$ 0.001. Clusters of activated pixels were then identified, based on the intensity of the individual responses and the spatial extent of the clusters. Finally, a significance threshold of $p=0.05$ (corrected for multiple comparisons) was applied for identification 
of the activated clusters. The results of the fixed effect group and random effects analyses are reported here.

\section{RESULTS}

\section{Audio results}

An example of analysis of the acoustic recordings with the Praat software is given in Figure 1, which displays the acoustic waveform (top panel), the spectrogram with the superimposed fundamental frequency (F0) curve (middle panel) and the duration and intonation labelling (bottom panels).

\section{Insert Figure 1 about here}

The mean utterance duration was $1139 \mathrm{~ms}$ (standard deviation: $159 \mathrm{~ms}$ ) before and $1108 \mathrm{~ms}$ (standard deviation: $129 \mathrm{~ms}$ ) after the scans. The mean sentence durations for each condition are shown in Table 1.

\section{Insert Table 1 about here}

An example of intonation analysis is provided in Figure 1 for one repetition of the prosodic deixis sentence by speaker DB. The rise towards the high pitch accent ${ }^{\mathrm{ii}}$, corresponding to the F0 peak on the first syllable /ma/, is labelled as LHf (Low High sequence with focus). The post-focal F0 trace falls to a flat floor (the fall is labelled as two L\%, i.e. two low Accentual Phrase boundary tones), which is a typical feature of French focus realizations (see Jun \& Fougeron, 2000 for a model of focus intonation in French). Different subjects made different choices as to the syllable bearing the high 
pitch accent in the prosodic deixis and combined deixis conditions, but their choices were maintained between measurements. To be more specific, in the prosodic deixis condition, the focused constituent being /ma.də.len/, three syllables were possible slots for the high pitch accents. In the combined deixis condition, 2 slots were available (/ma.dlen/). Overall, although inter-speaker variability was observed, no significant intra-speaker variability was detected between recordings. For instance, in the 4 repetitions of the prosodic deixis condition, 5 subjects put a high pitch accent on the first syllable (/ma/), 5 subjects promoted the second syllable (/də/), 4 subjects promoted the last syllable (/len/) and 2 subjects alternated between the second and third syllables. But, for each subject, the association between pitch accent and syllable did not vary between recordings.

Overall, the subjects' performances as measured by the audio recordings indicated that there was no intra-speaker variability neither in rhythm nor in intonation between recordings.

\section{FMRI Results}

Table 2 represents the peaks of activations and their corresponding stereotaxic Talairach coordinates, provided by the fixed effect analysis. Figures 2-4 represent the functional activations obtained for the main effects with the fixed effect analysis.

Insert Table 2 about here

The pattern of activations common to the three deixis conditions (each compared to the baseline) included parts of the LIFG (BA 45, 47), the left insula and the premotor cortex (BA 6) bilaterally. Prosodic deixis additionally activated the left anterior 
cingulate gyrus (BA 24, 32), the left supramarginal gyrus (LSMG, BA 40) and the left postero-superior temporal gyrus (Wernicke's area, BA 22).

The (prosodic deixis - syntactic deixis) contrast yielded significant activation in the left posterosuperior temporal gyrus and the LSMG.

\section{Insert Figures 2-4 about here}

The results of the random effect analysis, using the same statistical significance threshold $(\mathrm{p}=0.001$ corrected), for the same contrasts did not provide significant activations. With a less stringent significance threshold however ( $\mathrm{p}=0.05$ non corrected), the contrasts provide a similar pattern of activations as the one obtained with the fixed effect analysis.

\section{DISCUSSION}

\section{Baseline condition}

No "resting" condition was included in the paradigm. The adequacy of using the "resting state" in fMRI studies on cognition is a matter of debate. While it is generally accepted that the "resting" state involves activity within many brain regions, some authors (Mazoyer, Zago, Mellet, Bricogne, Etard, Houdé et al., 2001; Raichle, MacLeod, Snyder, Powers, Gusnard \& Shulman, 2001) consider that it nevertheless may constitute an adequate control condition in functional imaging studies on cognition. The hypotheses underlying this opinion are that the "resting" state corresponds to a welldefined baseline cognitive state presenting specific electroencephalographic and metabolic signatures and involving a specific network of cortical areas, and that the 
brain activity specific to the "resting" state is interrupted and temporarily suspended during the performance of cognitive tasks.

The concept of a "stationary level of activity" maintained during the "resting" state is however debated, as by Laufs, Krakow, Sterzer, Eger, Beyerle, Salek-Haddadi et al. (2003), asserting that "instead of globally stabilizing at a homogeneous baseline level, brain activity fluctuates within and between different modes that imply different segregated functional networks and have distinct EEG signatures".

The mental processes taking place during the "resting" state thus seem by no means well-defined. Furthermore, since certain studies have indicated the involvement of semantic processes during the "resting" state (e.g. Binder, Frost, Hammeke, Bellgowan, Rao \& Cox, 1999) and since the monitoring of thematic roles may be related to semantic processing, we have preferred not to use the "resting" state as baseline condition. The baseline condition used in this study therefore involved covert production - without prosodic deixis - of the sentence used in the prosodic deixis condition. With this particular choice, the activations obtained in the three (deixis baseline) contrasts are specific of deixis production rather than of deixis in combination with covert speech production.

\section{Thematic role monitoring}

The production of the three deictic sentences (conditions 2, 3 and 4) should involve thematic role monitoring, or the tracking of "who-did-what-to-whom", since they operate a contrastive pointing at one specific agent of the action (Madeleine). The prosodic deixis condition (2) involves no phrasal constituent movement, whereas both the syntactic (3) and the combined deixis (4) conditions involve cleft-sentences which can be analysed (in a Chomskyan framework) as requiring a transformational movement. 


\section{Habituation effects}

Only four sentences were used over and over again. The subjects had been extensively trained to task performance the day before the experiment, with the same four sentences. In doing so, we ensured correct task performance during the fMRI experiment (the pre- and post-scan audio recordings used the same four sentences and thus allowed assessment of the subjects' performance during the scan). We also ensured that task performance was practically effortless for the subjects. Thus, habituation effects may have taken place. Subjects needed to be skilled, however. The study therefore addresses the production of deictic sentences in a practiced mode.

\section{Audio results}

The baseline and prosodic conditions involved the same three words (Madeleine m'amena, /ma.də.len.ma.mə.na/ ) and the syntactic and combined conditions used the same five words (c'est Mad'leine qui m'am'na, /sc.ma.dlen.ki.ma.mna/). Although schwa deletion was imposed to maintain a same number of syllables (six) in the two sets, a slight duration difference is observed (Table 1). The mean durations for the threeword set are lower than those for the five-word set of sentences, by at most $205 \mathrm{~ms}$ before and $184 \mathrm{~ms}$ after the scans. This difference is of the order of a typical syllable duration in French (about $200 \mathrm{~ms}$ ) and is due to the presence of two longer syllables in the five-word set (/dlen/ and /mna/).

\section{Left Inferior Frontal Gyrus}

This fMRI study shows activation in the LIFG for all the deixis conditions compared with the baseline. The LIFG was therefore activated during verbal pointing at the agent of the action, through either prosody or syntax. 
In an attempt to relate the deficits of Broca's aphasics to current linguistic theoretical frameworks, Grodzinsky has concluded that the LIFG must have a highly specific, double role (Grodzinsky, 2000). In speech comprehension, it would process the transformational movement in syntax (Chomsky, 1981) $)^{\mathrm{iii}}$. The receptive deficit of Broca's aphasics would be one of trace deletion, and hence of thematic role misinterpretation. In speech production, the LIFG would be involved in the construction of the upper parts in the hierarchical structure (or tree) of sentences. The productive deficit of Broca's aphasics would be due to syntactic-tree pruning, whereby the syntactic tree would remain intact up to the tense node and be pruned from this node and up ${ }^{\text {iv }}$. This interpretation may explain why Broca's aphasics often make tense errors ("six months ago my mother pass away") while producing correct agreements ("the boy

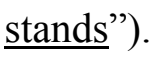

Our results are difficult to reconcile with Grodzinsky's claim that the LIFG is devoted to trace maintenance in thematic-role interpretation and full-fledged syntactic tree construction (i.e. with a preserved tense node) in speech production and that "processes underlying these highly structured syntactic abilities, and only these, are located in the anterior language areas" (Grodzinsky, 2000). They show, in contrast, that the LIFG is not devoted to trace maintenance and tense processing only. The prosodic deixis condition and the baseline condition used in our fMRI study had exactly the same syntactic constituents, in the same order, and exactly the same tense. They only differed in the presence or absence of a prosodic focus on the agent of the action. The prosodic deixis condition therefore did not involve more trace maintenance or more tense processing than the baseline condition. Yet, the (prosodic deixis - baseline) contrast revealed activation in the LIFG. 
Certain studies have suggested that the LIFG is involved in subvocal rehearsal, one of the components of the phonological/articulatory loop of verbal working memory (Paulesu, Frith \& Frackowiak,1993; Poeppel, 1996; Schumacher, Lauber, Awh, Jonides, Smith \& Koeppe, 1996; Dronkers, 2000). This led to the hypothesis, formulated by Stowe and colleagues (Stowe, Broere, Paans, Wijers, Mulder, Vaalburg et al., 1998; Stowe, 2000; see also Kaan \& Swaab, 2002), that the LIFG primarily supports temporary storage of verbal (including structural) information.

The involvement of the LIFG in the subvocal rehearsal component has however not always been observed (Lassen \& Larsen, 1980). Also, subvocal rehearsal was purposely limited in Caplan et al.'s (2000) PET study, yet LIFG activation was observed. While subjects performed a plausibility judgment task on syntactically complex constructions, a task requiring intricate thematic-role tracking, they were concurrently engaged in a repetitive simple articulation task. The increase of LIFG activity with the complexity of syntactic structures observed in the latter study must therefore most likely be ascribed to the parsing of the thematic roles rather than to subvocal rehearsal of more complex sentences. Finally, our own results do not support the hypothesis that the LIFG is simply involved in storage. The prosodic deixis condition does not involve more storage than the baseline condition, at least in terms of the number of phonemes or words, yet the (prosodic deixis - baseline) contrast shows LIFG activation.

The activation of the LIFG observed during verbal pointing at the agent of an action is consistent with functional neuroimaging studies on complex syntactic processing (Just et al., 1996; Caplan et al., 2000). As mentioned before, these studies have shown the involvement of the LIFG in plausibility judgments about syntactically 
complex constructions (with cleft-object sentences, or sentences with center-embedded clauses), the latter requiring intricate tracking of thematic roles.

Our findings are also in line with studies on the observation and mental imagery of action which show LIFG activation in action tracking (Grafton et al., 1996; Rizzolatti et al., 1997; Iacoboni et al., 1999; Binkofski et al., 2000). According to Rizzolatti and colleagues, the role of the LIFG in speech would have evolved from a "basic mechanism originally not related to communication: the capacity to recognize actions" (Rizzolatti \& Arbib, 1998).

Taken together, these observations support our claim that the role of the LIFG is that of an action-structure parser, which, in morphosyntactic encoding and decoding, handles the parsing of the predicate and its arguments, or, in other terms, the attentional monitoring of "who-does-what-to-whom".

\section{Functional dissociation within the LIFG}

Peak activation was observed in the anterior portion of the LIFG, i.e. in BA 45 and/or BA 47, not in BA44. Although most brain areas (Brett, Johnsrude \& Owen, 2002), and BA 44 and 45 more specifically (Amunts, Schleicher, Bürgel, Mohlberg, Uylings \& Zilles, 1999), cannot be precisely delineated from functional imaging data, this finding deserves comment. Several functional separations have been suggested to exist within the LIFG. The first separation distinguishes those areas involved in semantic and in phonological processing. On the basis of a review of several neuroimaging and neuropsychological studies, Fiez (1997) has suggested that the anterior ventral prefrontal cortex (BA47/10) may be involved in semantic processing while the posterior regions of the LIFG, i.e. the pars triangularis and opercularis (BA 44/45) may contribute to phonological processing. A similar functional dissociation is argued for by Poldrack, Wagner, Prull, Desmond, Glover \& Gabrieli (1999). On the 
basis of a literature review and of a new fMRI study they show that the ventral aspect of the LIFG (BA 47/45) is active during semantic tasks, whereas the dorsal aspect, near to the inferior frontal sulcus (BA 44/45), is active during both semantic and phonological tasks, probably supporting the phonological processes involved in both tasks. McDermott, Petersen, Watson \& Ojemann (2002) also argue for the functional distinction between anterior/ventral BA 47 and posterior/dorsal BA44/45, the former being involved in semantic processing and the latter in phonological processing. In addition, they suggest a further distinction within the dorsal/posterior LIFG: the more anterior component (BA 44/45) would be aligned with semantic processing and the more posterior portion (BA 6/44) would be involved in phonological processing.

The second important functional dissociation within the LIFG concerns syntax and semantics. Dapretto \& Bookheimer (1999) have suggested that the pars opercularis (BA44) is involved in syntax while pars orbitalis (BA 47) would be involved in semantics. Involvement of left BA 44 during syntactic processing in sentence comprehension has been reported by Stromswold et al. (1996) and by Caplan, Alpert \& Waters (1998). Left BA 44 has also been shown to be involved during syntactic encoding in overt speech production (Indefrey, Brown, Hellwig, Amunts, Herzog, Seitz et al., 2001). Other imaging or transcranial magnetic stimulation studies show that syntactic processing in fact involves pars triangularis (BA 45) (Caplan, Alpert \& Waters, 1999, Ben-Shachar, Hendler, Kahn, Ben-Bashat \& Grodzinsky, 2003) or both BA 44 and 45 (Just et al., 1996; Caplan et al., 2000; Embick, Marantz, Miyashita, O'Neil \& Sakai, 1997; Moro, Tettamanti, Perani, Donati, Cappa \& Fazio, 2001; Sakai, Noguchi, Takeuchi \& Watanabe, 2002).

While this large body of studies suggests a functional dissociation (semantics $v s$. syntax) between the anterior and posterior parts of the LIFG, Ni, Constable, Mencl, 
Pugh, Fulbright, Shaywitz et al. (2000) report activation of BA 44, 45 and 47 (predominantly in the left hemisphere) for semantic as well as for syntactic judgment tasks. In addition, as argued in Friederici (2002), syntactic and semantic processes do interact in a late stage of auditory sentence comprehension. According to Friederici, thematic role assignment which involves lexical-semantic and morpho-syntactic processes recruits both the anterior (BA 45/47) and the posterior (BA 44/45) portions of the LIFG.

Also, reports of LIFG activation during action observation do not support a clear functional separation between BA 44, 45 and 47. Left BA 44 has been shown to be recruited in imagery of grasping, in meaningful or goal-directed arm/hand action observation, meaningful mouth action observation or lip form/movement reading (Grafton et al., 1996; Iacoboni et al., 1999; Binkofski et al., 2000; Nishitani \& Hari, 2000; Nishitani \& Hari, 2002; Buccino et al., 2001; Grèzes et al., 1998; Koski, Wohlschläger, Bekkering, Woods, Dubeau, Mazziotta et al., 2002; Calvert \& Campbell, 2003). Left BA 45 has been shown to be involved in meaningful hand/mouth action observation or lip form/movement reading (Grafton et al., 1996; Grèzes et al., 1998; Buccino et al., 2001; Nishitani \& Hari, 2002; Calvert \& Campbell, 2003). Left BA 47 has recently been shown to be involved in lip reading (Calvert \& Campbell, 2003; Buccino, Lui, Canessa, Patteri, Lagravinese, Benuzzi et al., 2004).

In summary, while precise delineation within the IFG is obviously difficult, a number of studies have suggested an anterior-posterior functional dissociation within the LIFG. Posterior LIFG has been associated with phonological or syntactic processing while anterior LIFG has been associated with semantic processing. Other studies suggest that portions BA 44, 45 and 47 are all activated for both semantic and syntactic tasks. Thematic role monitoring, which is the focus of the present study, has also been shown 
to involve all three portions. Furthermore action monitoring (and especially lip reading) seems also to recruit all three portions. The peak activation detected in the anterior part of the LIFG provides additional ground to the hypothesis of functional segregation. The impossibility to precisely localize the activations with respect to the cytoarchitectonic areas within the LIFG leads us to express a comment of caution not to overinterpret this observation.

\section{Left Insula}

The left insula was also found activated in all the (deixis - baseline) contrasts. The involvement of the left precentral gyrus of the insula in articulatory planning during speech has already been shown (Dronkers, 1996). Prosody has both acoustic (variations in the fundamental frequency) and articulatory correlates (Beckman, Edwards \& Fletcher, 1992; Fougeron \& Keating, 1997; Lœvenbruck, 1999). The production of prosodic focus may require more precise laryngeal control as well as more accurate articulatory planning of the movements of the tongue and jaw, which could underly why the prosodic deixis condition yields significant activation of the left insula when compared with the baseline condition (same words to articulate, but a more stringent prosody). Similarly, the syntactic deixis condition compared with the baseline condition likely requires more accurate articulatory planning, given the larger number of consonant clusters involved (due to the schwa deletions imposed to keep the number of syllables constant).

\section{Wernicke's area, Left Supramarginal Gyrus, and Left Inferior Frontal Gyrus}

The activation of the left supramarginal gyrus and of Wernicke's area in the prosodic deixis condition but not in the other two deixis conditions suggests that, when deixis is already encoded by syntax, no additional recruitment of Wernicke's area and of 
the posterior parietal lobule is necessary. The posterior parietal lobule is often considered an association area, part of a network for spatial awareness, that integrates distributed multimodal sensory signals (somatosensory, visual, auditory) to form an interactive representation of space (Andersen, 1997; Mesulam 1981, 1999). Among the extensive body of research on the role of the posterior/inferior parietal cortex, two sets of findings are of particular interest in the present study.

The first set of observations deals with the role of the posterior parietal regions of both hemispheres in linguistic and non linguistic manual pointing tasks. It has been suggested that the spatial representations formed in the posterior parietal and premotor frontal regions could provide "perceptual - premotor interfaces for the organization of movements (e.g. pointing, locomotion) directed towards targets in personal and extrapersonal space" (Vallar, 1997, our underlining). This hypothesis is supported by the observation that patients with lesions in the right inferior posterior parietal region (and more specifically in the supramarginal gyrus, Vallar \& Perani, 1986) often show motor impairment, in addition to the typical perceptual spatial hemineglect. Furthermore, in a study on two right brain-damaged patients with left visuospatial hemineglect, Vallar and colleagues showed that the sensory stimulations (moving luminous dots) that modulate the severity of the left somatosensory deficits similarly modulate the left motor disorders (improve muscle strength) associated with this syndrome (Vallar, Guariglia, Nico \& Pizzamiglio, 1997). Also, in agreement with this hypothesis, patients with left unilateral neglect have been shown to present deficits in pointing tasks (e.g. Edwards \& Humphreys, 1999) while PET studies on normal subjects show activation within the left and/or right inferior parietal lobule (IPL) during pointing tasks (e.g. Lacquaniti, Perani, Guigon, Bettinardi, Carrozzo, Grassi et al., 1997; Kertzman, Schwarz, Zeffiro \& Hallett, 1997). The role of the right and left posterior/inferior parietal regions in pointing tasks 
may further be related to data on brain-damaged deaf signers. Bellugi and colleagues presented a study of deaf signers of American Sign Language (ASL), two of which presented lateralized parietal lesions, one in the right hemisphere and the other in the left (Bellugi, Poizner \& Klima, 1989). Space in ASL is handled in two ways. The first is topographic: in the description of the layout of objects in space, spatial relations among signs reproduce the actual spatial relations among the objects. The second way is deictic: space is used for referential indexing. Noun phrases, for instance, may be associated with loci in space. Reference to a previously mentioned noun is performed by pointing again to its specific locus. Interestingly, the right-lesioned signer had difficulty in the use of space for topography: room description was distorted spatially, with left side of signing space neglected. In the use of space for syntax, however, the entire signing space (including the left) was covered and consistent reference to spatial loci was preserved. By contrast, the left-lesioned signer produced room descriptions without spatial distortions but made errors in the deictic use of space. These results could suggest a differential lateralization of IPL activity, with the right IPL involved in non linguistic pointing tasks and the left IPL involved in linguistic manual pointing (in sign language). Conflicting data have been reported by some recent studies in this respect.. As to non linguistic pointing, Lacquaniti et al. (1997) have reported left IPL activation for immediate pointing to a target and bilateral IPL activation for pointing to a memorized target. Their interpretation is that the decoding of a memorized location in a body-centered frame (to direct the pointing movement) is handled in the right IPL. A left lateralization of the IPL activation is also found by Astafiev, Shulman, Stanley, Snyder, Van Essen \& Corbetta (2003) for non linguistic pointing as well as pointing preparation. In a recent study on (non verbal) action monitoring, Chaminade \& Decety (2002) have suggested that the hemispheric asymmetry observed for the IPL may be related to 
agency. They demonstrated that the left IPL is more activated when subjects imitate the actions by others (subject in a follower role), while the right IPL is more activated when the self is imitated (subject in a leader role). The asymmetry is also found in linguistic processing of spatial relations. Recent data on IPL lateralization during the production or comprehension of topographical relations in sign language are discussed by Campbell \& Woll (2003). Thus, while it appears that the left IPL is involved in linguistic manual pointing (sign language), its implication in some non linguistic pointing and in the monitoring of the other suggests the need for further clarification of its role in pointing. The second set of findings concerns the role of the left inferior parietal cortex in verbal working memory. Some neuroimaging studies of verbal working memory have shown the implication of the left inferior parietal cortex in short-term storage of phonologically coded verbal material (see e.g. Paulesu et al., 1993; Jonides, Schumacher, Smith, Koeppe, Awh, Reuter-Lorenz et al., 1998). Hickok and Poeppel offer a hypothesis which can account for these results by analogy with the visual - motor interface system presented above. According to these authors, "inferior parietal cortex is not the site of storage of phonemic representations per se (...) but rather serves to interface soundbased representations of speech in auditory cortex with articulatory-based representations of speech in frontal cortex" (Hickok \& Poeppel, 2000). In analogy with the dorsal pathway hypothesized in audition and vision, the left inferior parietal cortex would therefore play a role within a temporo-parieto-frontal network functioning as an interface system between auditory and articulatory processes. Involvement of this temporo-parieto-frontal circuit has also been described in action imitation (Iacoboni, Koski, Brass, Bekkering, Woods, Dubeau et al., 2001). Iacoboni and colleagues conjecture that the description of the actions to be imitated is handled by the superior temporal sulcus (STS) and sent to the posterior parietal cortex, where it is combined 
with additional somatosensory information. This completed description would then be sent to the inferior frontal cortex where the goal of the actions to be imitated would be coded. Reafferent copies of the imitated actions would be sent back to the STS for action monitoring.

In summary, all these studies suggest that the inferior parietal regions in both hemispheres function as sensory integrators to form representations necessary in the organization of motor actions, such as (linguistic or non-linguistic) pointing at targets. The left hemisphere would have a linguistic predominance. A left temporo-parietofrontal network might be recruited in the organization of verbal motor actions from auditory representations.

Our results, i.e. the activations of the left inferior parietal lobule together with the LIFG and Wernicke's area during prosodic deixis, are in line with this hypothesis. Prosodic deixis, i.e. expressive orofacial (manual and facial for sign language) deixis may be considered in continuity with manual pointing. In analogy with visually-guided manual pointing, prosodic pointing may need integrated representations (auditory and articulatory) to be formed via the superior temporal and inferior parietal regions in order to organize articulation and phonation in an adequate prosodic pattern.

We therefore hypothesize that non-grammaticalized verbal pointing recruits the temporo-parieto-frontal network and that grammaticalized deixis (syntactic deixis with or without supplementary prosody) is handled solely by the left IFG. Further experiments based on gradual grammaticalization tasks are needed to clarify matters.

\section{CONCLUSION}

While "basic" linguistic information recruits the left hemisphere, prosody is traditionally considered to be processed by the right hemisphere (Ross, 1981; 
Weintraub, Mesulam \& Kramer, 1981; Klouda, Robin, Graff-Radford \& Cooper, 1988; Twist, Squires, Spielholz \& Silverglide, 1991; Brådvik, Dravins, Holtås, Rosén, Ryding \& Ingvar, 1991; Dronkers, Pinker \& Damasio, 2000), a view reflecting the traditional conception of prosody as a well adapted subordinate to syntax and semantics. Several recent neuroimaging studies provide data supporting this view. When aspects of prosody associated with melody processing are studied, activation in the right hemisphere is found indeed (see e.g. Zatorre, Evans, Meyer \& Gjedde, 1992; Tzourio, El Massioui, Crivello, Joliot, Renault \& Mazoyer, 1997; Meyer, Alter, Friederici, Lohmann \& von Cramon, 2002). Recent studies have shown that prosody is itself a "complex grammatical (phonological) structure that must be parsed in its own right" (Beckman, 1996), however. Prosody, therefore, should recruit the left hemisphere, similarly as syntax and semantics. Interestingly, a recent review of the literature (Baum \& Pell, 1999) shows that the processing (in production and perception) of prosody in general (affective and linguistic) is not strictly localizable to the right hemisphere. More specifically, this review quotes studies on the production and on the perception of emphasis (which is related to prosodic focus) showing that left-damaged patients (most often Broca's aphasics) are more strongly impaired than right-damaged patients. Recent neuroimaging studies also provide converging results. Astésano and colleagues (Astésano, Besson \& Alter, 2004) present electrophysiological evidence that attention to prosody (detection of prosodic mismatch) primarily recruits the left hemisphere. Incidentally, they also report that the electrophysiological response P800 has a larger amplitude at temporo-parietal electrodes, in accordance with our own results showing activations of the LSMG and Wernicke's area in the prosodic task. A number of fMRI studies on the receptive processing of several aspects of prosody also show activation in the left IFG (Dapretto, Hariri, Bialik \& Bookheimer, 1999). In addition, Mayer and 
colleagues's fMRI study on the production of prosodic features at the syllable and phrase levels has also revealed left IFG activation (Mayer, Wildgruber, Riecker, Dogil, Ackermann \& Grodd, 2002). We consider that these results are consistent with our two conjectures: the LIFG being a parser of action structure, particularly well adapted to agent deixis and the left temporo-parieto-frontal network functioning as an interface between auditory and articulation/phonation processes, required in prosody-driven deixis.

\section{ACKNOWLEDGEMENTS}

We are very grateful to Véronique Aubergé and Pascal Perrier for valuable comments and advice and to Chantal Delon-Martin for her assistance with the statistical analysis of the fMRI data. We also thank Cécile Brichet, Christophe Savariaux, Chafika Rabehi \& Albert Rilliard for discussion. This research was supported by the grant "Aide à Projets Nouveaux" of the SHS department of the CNRS, project \# 29031.

\section{REFERENCES}

Amunts K, Schleicher A., Bürgel U., Mohlberg H., Uylings H. B. M., Zilles K. (1999). Broca's region revisited: cytoarchitecture and intersubject variability. J. Comp. Neurol., 412, 319-341.

Andersen R. A. (1997). Multimodal integration for the representation of space in the posterior parietal cortex. Philos. Trans. R. Soc. Lond. B. Biol. Sci., 352(1360), 1421-1428.

Astafiev S. V., Shulman G. L., Stanley C. M., Snyder A. Z., Van Essen D. \& Corbetta M. (2003). Functional organization of human intraparietal and frontal cortex for attending, looking and poiting. J. Neuroscience, 23 (11), 4689-4699.

Astésano C., Besson M. \& Alter K. (2004). Brain potentials during semantic and prosodic processing in French. Cognitive Brain Research, 18, 172-184. 
Baum S. R. \& Pell M. D. (1999). The neural bases of prosody: insights from lesion studies and neuroimaging. Aphasiology, 13 (8), 581-608.

Beckman M. E. (1996). The parsing of prosody. Language and Cognitive Processes, 11 (1/2), 17-67.

Beckman M. E., Edwards J. \& Fletcher J. (1992). Prosodic structure and tempo in a sonority model of articulatory dynamics. Papers in Laboratory Phonology II; Gesture, segment, prosody. G. J. Docherty \& D. R. Ladd (eds.), Cambridge University Press. 68-86.

Bellugi U., Poizner H. \& Klima E. S. (1989). Language, modality and the brain. Trends in Neurosciences, 12 (10), 380-388.

Ben-Shachar M., Hendler T., Kahn I., Ben-Bashat D. \& Grodzinsky Y. (2003). The neural reality of syntactic transformations: evidence from functional magnetic resonance imaging.. Psychological Science, 14 (5), 433-440.

Berthoud A.-C. (1990). Deixis, thématisation et détermination. La deixis. Colloque en Sorbonne. M.-A. Morel \& L. Danon-Boileau (dir.), PUF, 527-542.

Binder J. R., Frost J. A., Hammeke T. A., Bellgowan P. S., Rao S. M. \& Cox R. W. (1999). Conceptual processing during conscious resting state. A functional MRI study. J. Cognitive Neuroscience, 11 (1), 80-95.

Binkofski F., Amunts K., Stephan K. M., Posse S., Schormann T., Freund H.-J., Zilles K. \& Seitz R. (2000). Broca's region subserves imagery of motion: a combined cytoarchitectonic and fMRI study. Hum. Brain Mapp., 11, 273-285.

Boersma P. (2001). PRAAT, a system for doing phonetics by computer. Glot International, 5(9/10), 341-345.

Brådvik B., Dravins C., Holtås S., Rosén I., Ryding E. \& Ingvar D. (1991). Disturbances of speech prosody following right hemisphere infarcts. Acta Neurologica Scandinavia, 84, 114-126.

Brett M., Johnsrude I. S. \& Owen A. M. (2002). The problem of functional localization in the human brain. Nature Reviews Neuroscience, 3 (3), 243-249.

Broca P. (1861). Remarques sur le siège de la faculté du langage articulé, suivies d'une observation d'aphémie (perte de la parole). Bulletin de la Société d'Anatomie de Paris, 6, 330-357.

Buccino G., Binkofski F., Fink G. R., Fadiga L., Fogassi L., Gallese V., Seitz R. J., Zilles K., Rizzolatti G. \& Freund H.-J. (2001). Action observation activates 
premotor and parietal areas in a somatotopic manner: an fMRI study. European Journal of Neuroscience, 13, 400-404.

Buccino G., Lui F., Canessa N., Patteri I., Lagravinese G., Benuzzi F., Porro C. A., Rizzolatti G. (2004). Neural circuits involved in the recognition of actions performed by nonconspecifics: an fMRI study. J. Cogn. Neurosci. , 16(1), 114216.

Calvert G. A. \& Campbell R. (2003). Reading speech from still and moving faces: the neural substrates of visible speech. J. Cognitive Neuroscience, 15 (1), 57-70.

Campbell R. \& Woll B. (2003). Space is special in sign. Trends in Cognitive Sciences, 17 (1), 5-7.

Caplan D., Alpert N., Waters G. (1998). Effects of Syntactic Structure and Propositional Number on Patterns of Regional Cerebral Blood Flow. J. Cognitive Neuroscience, $10,541-552$.

Caplan D., Alpert N. \& Waters G. (1999). PET studies of syntactic processing with auditory sentence presentation. NeuroImage, 9, 343-351.

Caplan D., Alpert N., Waters G. \& Olivieri A. (2000). Activation of Broca's area by syntactic processing under conditions of concurrent articulation. Hum. Brain Mapp., 9, 65-71.

Caramazza A. \& Zurif E. B. (1976). Dissociation of algorithmic and heuristic processes in language comprehension: evidence from aphasia. Brain and Language, 3 (4), $572-582$.

Chaminade T. \& Decety J. (2002). Leader of follower? Involvement of the inferior parietal lobule in agency. Neuroreport, 13 (15), 1975-1978.

Chomsky N. (1981). Lectures on government and binding. Foris.

Dapretto M. \& Bookheimer S. Y. (1999). Form and content: dissociating syntax and semantics in sentence comprehension. Neuron, 24, 427-432.

Dapretto M., Hariri A., Bialik M. \& Bookheimer S. (1999). Cortical correlates of affective vs. linguistic prosody: an fMRI study. NeuroImage, 9 (6), S1054.

Démonet J. -F., Price C., Wise R. \& Frackowiak R. S. J. (1994). A PET study of cognitive strategies in normal subjects during language tasks: Influence of phonetic ambiguity and sequence processing on phoneme monitoring. Brain, 117, 671-682. 
Dominey P. F. \& Lelekov T. (2000). Nonlinguistic transformation processing in agrammatic aphasia. Commentary/Grodzinsky: Neurology of syntax. Behavioral and Brain Sciences, 23, 30.

Dronkers N. F. (1996). A new brain region for coordinating speech articulation. Nature, $384,159-161$

Dronkers N. F. (2000). The gratuitous relationship between Broca's aphasia and Broca's area. Commentary/Grodzinsky: Neurology of syntax. Behavioral and Brain Sciences, 23 (1), 30-31.

Dronkers N. F., Pinker S. \& Damasio A. (2000). Language and the Aphasias. Principles of neural science, E. R. Kandel, J. H. Schwartz \& T. M. Jessell (eds.), McGrawHill. 1169-1187.

Edwards M. G. \& Humphreys G. W. (1999). Pointing and grasping in unilateral visual neglect: effect of on-line visual feedback in grasping. Neuropsychologia, 37 (8), 959-973.

Embick D., Marantz A., Miyashita Y., O'Neil W. \& Sakai K. L. (1997). A syntactic specialization for Broca's area. Proc. Natl. Acad. Sci., 97 (11), 6150-6154.

Fiez J. (1997). Phonology, semantics, and the role of the left inferior prefrontal cortex. Hum. Brain Mapp., 5, 79-83.

Fogassi, L. (2003) Action recognition in the primate motor cortex can be a basis for communication. Paper presented at the conference "Vocalize to localize: A missing piece in the puzzling route towards language”, Grenoble, January, 2003.

Fougeron C. \& Keating P. A. (1997). Articulatory strengthening at edges of prosodic domains. J. Acoust. Soc. Am. 101 (6), 3728-3740.

Friederici A. D. (1990). On the properties of cognitive modules. Psychol. Research, 52, 175-180.

Friederici A. D. (2002). Towards a neural basis of auditory sentence processing. Trends in Cognitive Sciences, 6 (2), 78-84.

Goschke T., Friederici A. D., Kotz S. A. \& van Kampen A. (2001). Procedural Learning in Broca's Aphasia: Dissociation Between the Implicit Acquisition of SpatioMotor and Phoneme Sequences. J. Cogn. Neurosci., 13, 370-388.

Grafton S. T., Arbib M. A., Fadiga L. \& Rizzolatti G. (1996). Localization of grasp representations in humans by positron emission tomography. 2. Observation compared with imagination. Exp. Brain Res., 112 (1), 103-11. 
Grèzes J. \& Decety J. (2001). Functional anatomy of execution, mental simulation, observation, and verb generation of actions: A meta-analysis. Hum. Brain Mapp., $12,1-19$.

Grèzes J., Costes N. \& Decety J. (1998). Top down effect of strategy on the perception of human biological motion: a PET investigation. Cogn. Neuropsychol., 15, 553582.

Grodzinsky Y. (2000). The neurology of syntax: Language use without Broca's area. Behavioral and Brain Sciences, 23 (1), 1-21.

Grodzinsky Y., Piñango M. M., Zurif E. \& Drai D. (1999). The critical role of group studies in neuropsychology: comprehension regularities in Broca's aphasia. Brain and language, 67 (2), 134-147.

Hickok G. (2000). The left frontal convolution plays no special role in syntactic comprehension. Commentary/Grodzinsky: Neurology of syntax. Behavioral and Brain Sciences, 23, 35-36.

Hickok G. \& Poeppel D. (2001). Towards a functional neuroanatomy of speech perception. Trends in Cognitive Sciences, 4 (4), 131-138.

Iacoboni M., Woods R. P, Brass M., Bekkering H., Mazziotta J. C. \& Rizzolatti G. (1999). Cortical mechanisms of human imitation. Science, 286, 2526-2528.

Iacoboni M., Koski L. M., Brass M., Bekkering H., Woods R.P, Dubeau M.-C., Mazziotta J. C. \& Rizzolatti G. (2001). Reafferent copies of imitated actions in the right superior temporal cortex. Proc. Natl. Acad. Sci. USA, 98 (24), 13995-13999.

Indefrey P., Brown C. M., Hellwig F., Amunts K., Herzog H., Seitz R. J. \& Hagoort P. (2001). A neural correlate of syntactic encoding during speech production. Proc. Natl. Acad. Sci., 98 (10), 5933-5936.

Jackendoff R. (2002). Foundations of Language - Brain, Meaning, Grammar, Evolution. Oxford University Press.

Jonides J., Schumacher E. H., Smith E. E., Koeppe R. A., Awh E., Reuter-Lorenz P. A., Marshuetz C., Willis C. R. (1998). The role of parietal cortex in verbal working memory. J. Neurosci., 18 (13), 5026-5034.

Jun S.-A. \& Fougeron C. (2000). A phonological model of French intonation. Intonation: Analysis, modeling and technology. A. Botinis (ed.) Dordrecht : Kluwer Academic Publishers. 209-242. 
Just M. A., Carpenter P. A., Keller T. A., Eddy W. F. \& Thulborn K. R. (1996). Brain activation modulated by sentence comprehension. Science, 274, 114-116.

Kaan E. \& Swaab T. Y. (2002). The brain circuitry of syntactic comprehension. Trends in Cognitive Sciences, 6 (8), 350-356.

Kertzman C., Schwarz U., Zeffiro T. A. \& Hallett M. (1997). The role of posterior parietal cortex in visually guided reaching movements in humans. Exp. Brain Res., 114 (1), 170-183.

Klouda G. V., Robin D. A., Graff-Radford N. R. \& Cooper W. E. (1988). The role of callosal connections in speech prosody. Brain Lang., 35 (1), 154-171.

Koski L., Wohlschläger A., Bekkering H., Woods R. P., Dubeau M.-C., Mazziotta J. C. \& Iacoboni M. (2002). Modulation of motor and premotor activity during imitation of target-directed actions. Cereb. Cortex, 12, 847-855.

Lacquaniti F., Perani D., Guigon E., Bettinardi V., Carrozzo M., Grassi F., Rossetti Y. \& Fazio F. (1997). Visuomotor transformations for reaching to memorized targets: a PET study. Neuroimage, 5 (2), 129-146.

Lassen N. A. \& Larsen B. (1980). Cortical activity in the left and right hemispheres during language-related brain functions. Phonetica, 37, 27-37.

Laufs H., Krakow K., Sterzer P., Eger E., Beyerle A., Salek-Haddadi A. \& Kleinschmidt A. (2003). Electroencephalographic signatures of attentional and cognitive default modes in spontaneous brain activity fluctuations at rest. Proc. Natl. Acad. Sci. USA, 100 (19), 11053-11058.

Levinson S. (1983). Pragmatics, Cambridge University Press, Cambridge, England.

Linebarger M. C., Schwartz M. F. \& Saffran E. M. (1983). Sensitivity to grammatical structure in so-called agrammatic aphasics. Cognition, 13 (3), 361-392.

Lœvenbruck H. (1999). An investigation of articulatory correlates of the accentual phrase in French. Proceedings of the XIVth International Congress of Phonetics Sciences, San Francisco, CA, August 1999, 1, 667-670.

Mattingley J. B., Husain M., Rorden C., Kennard C. \& Driver J. (1998). Motor role of human inferior parietal lobe revealed in unilateral neglect patients. Nature, 392 (6672), 179-182.

Mayer J., Wildgruber D., Riecker A., Dogil G., Ackermann H. \& Grodd W. (2002). Prosody production and comprehension: converging evidence from fMRI studies. 
Proceedings of Speech Prosody 2002, Aix-en-Provence, France, 11-13 April 2002, 487-490.

Mazoyer B., Zago L., Mellet E., Bricogne S., Etard O., Houdé O., Crivello F., Joliot M., Petit L. \& Tzourio-Mazoyer N. (2001). Cortical networks for working memory and executive functions sustain the conscious resting state in man. Brain Res. Bull., 54 (3), 287-298.

McDermott K. B., Petersen S. E., Watson J. M. \& Ojemann J. G. (2002). A procedure for identifying regions preferentially activated by attention to semantic and phonological relations using functional magnetic resonance imaging. Neuropsychologia, 41, 293-303.

Mesulam M. M. (1981). A cortical network for directed attention and unilateral neglect. Ann. Neurol., 10 (4), 309-325.

Mesulam M. M. (1999). Spatial attention and neglect: parietal, frontal and cingulate contributions to the mental representation and attentional targeting of salient extrapersonal events. Philos. Trans. R. Soc. Lond. B. Biol. Sci., 354 (1387), 13251346.

Meyer M., Alter K., Friederici A. D., Lohmann G. \& von Cramon D. Y. (2002). FMRI reveals brain regions mediating slow prosodic modulations in spoken sentences. Hum. Brain Mapp., 17, 73-88.

Moro A., Tettamanti M., Perani D., Donati C., Cappa S. F. \& Fazio F. (2001). Syntax and the brain: disentangling grammar by selective anomalies. NeuroImage, 13, 110-118.

Ni W., Constable R. T., Mencl W. E., Pugh K. R., Fulbright R. K., Shaywitz S. E., Shaywitz B. A., Gore J. C. \& Shankweiler D. (2000). An event-related neuroimaging study distinguishing form and content in sentence processing. $J$. Cognitive Neuroscience, 12 (1), 120-133.

Nishitani N. \& Hari R. (2000). Temporal dynamics of cortical representation for action. Proc. Natl. Acad. Sci. USA, 97 (2), 913-918.

Nishitani N. \& Hari R. (2002). Viewing lip forms: cortical dynamics. Neuron. 36 (6), 1211-1220.

Oldfield R. C. (1971). The assessment and analysis of handedness: the Edinburgh inventory. Neuropsychologia, 9 (1), 97-113. 
Paulesu E., Frith C. D. \& Frackowiak R. S. J. (1993). The neural correlates of the verbal component of working memory. Nature, 362, 342-344.

Penhune V. B., Zatorre R. J. \& Evans A. C. (1998). Cerebellar contributions to motor timing: A PET study of auditory and visual rhythm reproduction. J. Cogn. Neurosci., 10, 752-765.

Poeppel D. (1996). A critical review of PET studies of phonological processing. Brain and Language, 55(3), 317-351.

Poldrack R. A., Wagner A. D., Prull M. W., Desmond J. E., Glover G. H. \& Gabrieli J. D. E. (1999). Functional specialization for semantic and phonological processing in the left inferior prefrontal cortex. NeuroImage, 10, 15-35.

Pollock J.-Y. (1989). Verb movement, universal grammar and the structure of IP. Linguistic Inquiry, 20, 365-424.

Raichle M. E., MacLeod A. M., Snyder A. Z., Powers W. J., Gusnard D. A. \& Shulman G. L. (2001). A default mode of brain function. Proc. Natl. Acad. Sci., 98 (2), 676682.

Rizzolatti G., Fogassi L., Gallese V. (1997). Parietal cortex: from sight to action. Curr. Opin. Neurobiol., 7 (4), 562-567.

Rizzolatti G. \& Arbib M. (1998). Language within our grasp. Trends in Neurosciences, 21, 188-194.

Ross E. D. (1981). The aprosodias: functional-anatomic organization of the affective components of language in the right hemisphere. Arch. Neurol. 38, 561-569.

Sakai K. L., Noguchi Y., Takeuchi T. \& Watanabe E. (2002). Selective priming of syntactic processing by event-related transcranial magnetic stimulation of Broca's area. Neuron, 35, 1177-1182.

Schumacher E. H., Lauber E., Awh E., Jonides J., Smith E. E. \& Koeppe R. A. (1996). PET evidence for an amodal verbal working memory system. NeuroImage, 3 (2), 79-88.

Stowe L. A. (2000). Sentence comprehension and the left inferior frontal gyrus: Storage, not computation. Commentary/Grodzinsky: Neurology of syntax. Behavioral and Brain Sciences, 23 (1), 51.

Stowe L. A., Broere C. A., Paans A. M., Wijers A. A., Mulder G., Vaalburg W. \& Zwarts F. (1998). Localizing components of a complex task: sentence processing and working memory. NeuroReport, 9 (13), 2995-2999. 
Stromswold K., Caplan D., Alpert N. \& Rauch S. (1996). Localization of syntactic comprehension by positron emission tomography. Brain and Language, 52 (3), 452-473.

Twist D., Squires N., Spielholz N. \& Silverglide R. (1991). Event-related potentials in disorders of prosodic and semantic linguistic processing. Neuropsychiatry, Neurosurgery, and Behavioral Neurology, 4, 281-304. ${ }^{\circ} \mathrm{a}$ å

Tzourio N., El Massioui F., Crivello F., Joliot M., Renault B. \& Mazoyer B. (1997). Functional anatomy of human auditory attention studied with PET. NeuroImage, $5,63-77$.

Vallar G. (1997). Spatial frames of reference and somatosensory processing: a neuropsychological perspective. Philos. Trans. R. Soc. Lond. B. Biol. Sci., 352(1360), 1401-1409.

Vallar G. \& Perani D. (1986). The anatomy of unilateral neglect after right-hemisphere stroke lesions. A clinical/CT-scan correlation study in man. Neuropsychologia, 24 (5), 609-622.

Vallar G., Guariglia C., Nico D. \& Pizzamiglio L. (1997). Motor deficits and optokinetic stimulation in patients with left hemineglect. Neurology, 49 (5), 13641370 .

Weintraub S., Mesulam M. M. \& Kramer L. (1981). Disturbances in prosody. A righthemisphere contribution to language. Arch. Neurol., 38(12), 742-744.

Zatorre R. J., Evans A. C., Meyer E. \& Gjedde A. (1992). Lateralization of phonetic and pitch discrimination in speech processing. Science, 256, 846-849.

Zurif E. B. (1980). Language mechanisms: a neuropsychological perspective. American Scientist, 68(3), 305-311. 


\section{FIGURE CAPTIONS}

\section{Figure 1}

Acoustic analysis of one repetition of the prosodic deixis sentence by speaker DB. Top panel: acoustic waveform (top panel). Middle panel: spectrogram with superimposed F0 trace. Bottom panels: syllable duration and prosodic tiers. The high F0 peak on the first syllable /ma/ is labelled as LHf (Low High sequence with focus). The post-focal F0 trace falls to reach a flat floor (the fall is labelled as two low Accentual Phrase boundary tones, L\%). The same F0 and duration pattern is observed across the 8 repetitions by this speaker.

\section{Figure 2}

(Prosodic deixis - baseline) contrast. Projection of the activation foci onto the right and left lateral surfaces of a standard brain (MNI template).

\section{Figure 3}

(Syntactic deixis - baseline) contrast. Projection of the activation foci onto the right and left lateral surfaces of a standard brain (MNI template).

\section{Figure 4}

(Combined deixis - baseline) contrast. Projection of the activation foci onto the right and left lateral surfaces of a standard brain (MNI template). 



\section{Table 1}

Mean sentence duration and standard deviation (in $\mathrm{ms}$ ) for the 4 conditions, before and after the scans.

\begin{tabular}{|l|r|r|r|r|r|r|r|r|}
\cline { 2 - 9 } & \multicolumn{2}{c|}{ Baseline } & \multicolumn{2}{c|}{ Prosodic deixis } & \multicolumn{2}{c|}{ Syntactic deixis } & \multicolumn{2}{c|}{ Combined deixis } \\
\cline { 2 - 9 } & Mean & $\begin{array}{l}\text { Standard } \\
\text { deviation }\end{array}$ & Mean & $\begin{array}{l}\text { Standard } \\
\text { deviation }\end{array}$ & Mean & $\begin{array}{l}\text { Standard } \\
\text { deviation }\end{array}$ & Mean & $\begin{array}{l}\text { Standard } \\
\text { deviation }\end{array}$ \\
\hline Pre-scan & 1049 & 116 & 1052 & 114 & 1203 & 91 & 1254 & 155 \\
\hline Post-scan & 1011 & 108 & 1046 & 79 & 1189 & 83 & 1195 & 80 \\
\hline
\end{tabular}


Table 2

Talairach coordinates and Z-scores of activated regions in the deictic tasks.

\begin{tabular}{|c|c|c|c|c|}
\hline \multirow[t]{2}{*}{ Region } & \multicolumn{3}{|c|}{ Talairach coordinates (mm) } & \multirow[t]{2}{*}{ Z-scores } \\
\hline & $\mathrm{x}$ & y & $\mathrm{z}$ & \\
\hline \multicolumn{5}{|l|}{ Prosodic deixis - baseline } \\
\hline Left insula & -32 & 4 & 9 & $>8$ \\
\hline Left insula & -36 & -11 & 10 & 6.5 \\
\hline Left anterior cingulate (BA 24) & -12 & 5 & 18 & 5.1 \\
\hline LIFG (BA 47) & -32 & 20 & -5 & $>8$ \\
\hline Wernicke's area (BA 22) & -48 & -16 & 10 & 6.5 \\
\hline Left medial frontal gyrus (BA 6) & -28 & 2 & 46 & 7.3 \\
\hline Left anterior cingulate gyrus (BA 32) & -20 & 10 & 41 & 7.2 \\
\hline Left SMG (BA 40) & -44 & -37 & 34 & 6.6 \\
\hline Right SMA (BA 6) & 4 & -9 & 56 & 6.4 \\
\hline Right SMA (BA 6) & 16 & -9 & 56 & 6.1 \\
\hline \multicolumn{5}{|l|}{ Syntactic deixis - baseline } \\
\hline Left insula & -32 & 8 & 9 & 7.0 \\
\hline LIFG (BA 45) & -28 & 20 & 8 & 5.2 \\
\hline LIFG (BA 47) & -40 & 16 & -1 & 4.9 \\
\hline Left superior frontal gyrus (BA 8) & -20 & 14 & 50 & 6.4 \\
\hline Left medial frontal gyrus (BA 6) & -24 & 3 & 51 & 6.0 \\
\hline Left medial frontal gyrus (BA 6) & -24 & -9 & 56 & 5.2 \\
\hline
\end{tabular}

\section{Combined deixis - baseline}

Left insula

\begin{tabular}{rrrr}
-36 & 4 & 9 & 6.1 \\
-28 & 16 & 8 & 6.0 \\
-20 & 10 & 50 & 6.1 \\
-20 & -16 & 61 & 5.6 \\
-20 & 14 & 41 & 5.5 \\
\hline
\end{tabular}

\section{Prosodic deixis - syntactic deixis}

Left posterosuperior temporal gyrus (BA 22)

$\begin{array}{rrrr}-40 & -35 & 6 & 7.0 \\ -40 & -33 & 29 & 6.4 \\ -40 & -33 & 48 & 6.2\end{array}$

Left SMG (BA 40)

Left SMG (BA 40)

6.2

Note. Corresponding Brodmann's areas are given in parentheses; LIFG, Left Inferior Frontal Gyrus; SMA, Supplementary Motor Area; SMG, Supramarginal Gyrus. 
Figure 1

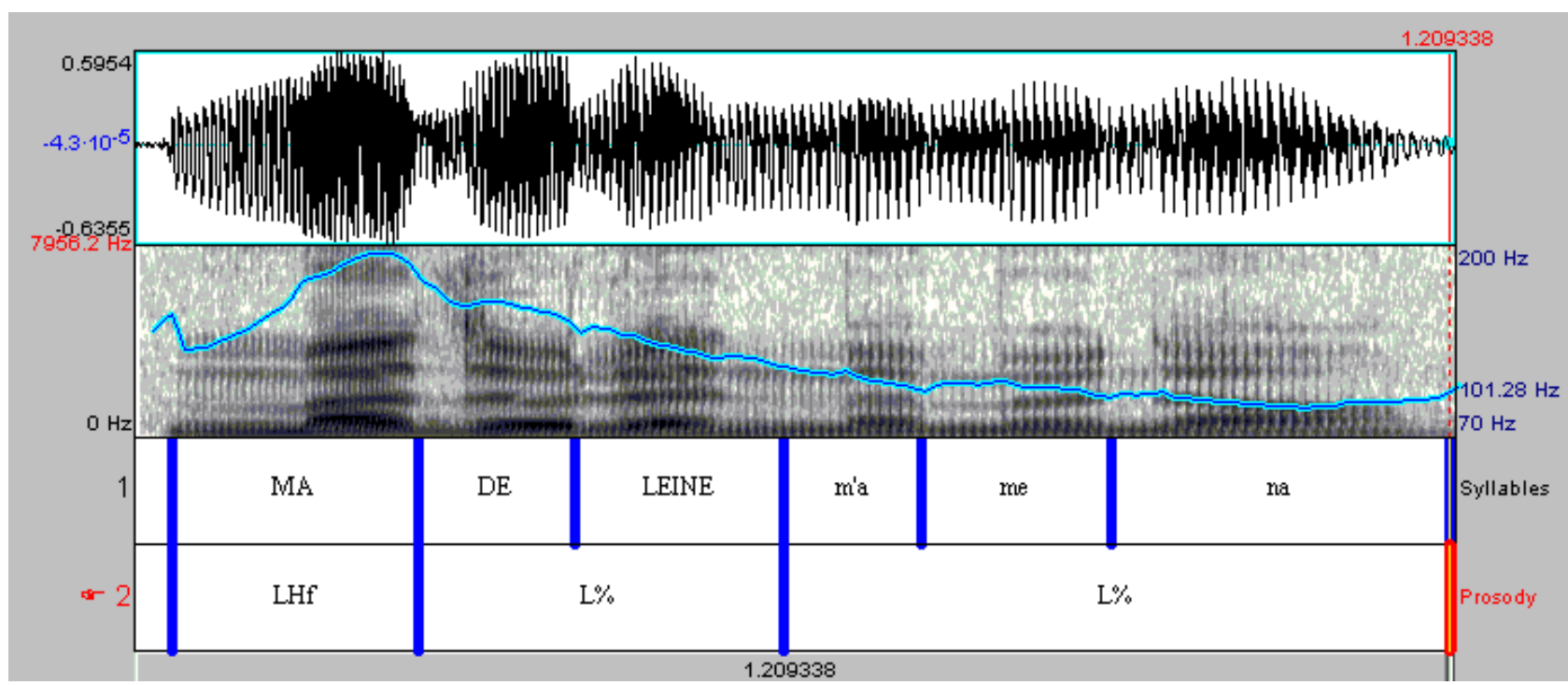


Figure 2

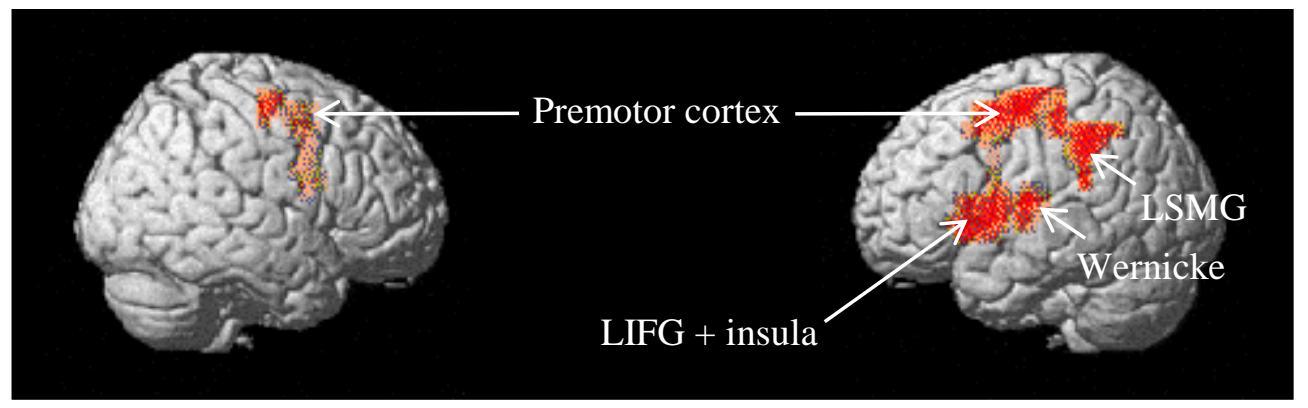


Figure 3

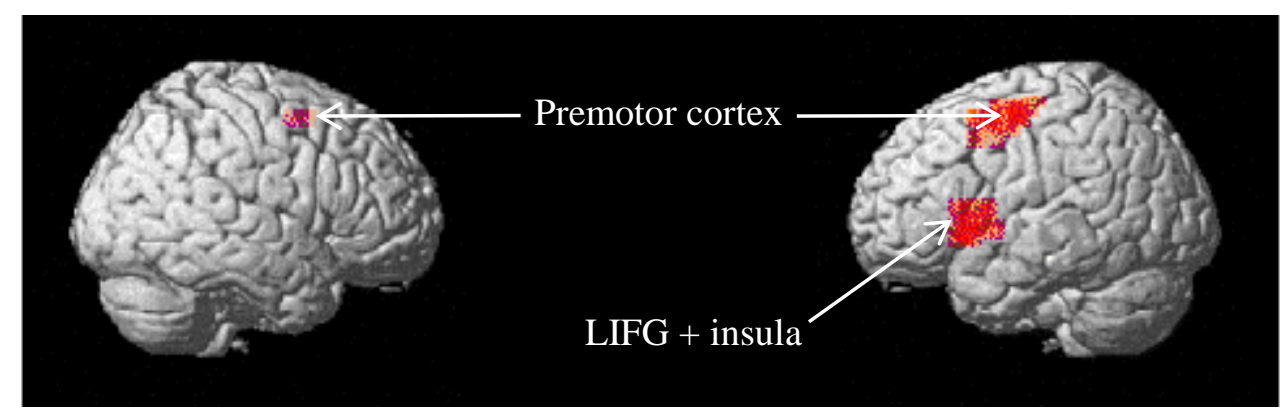


Figure 4

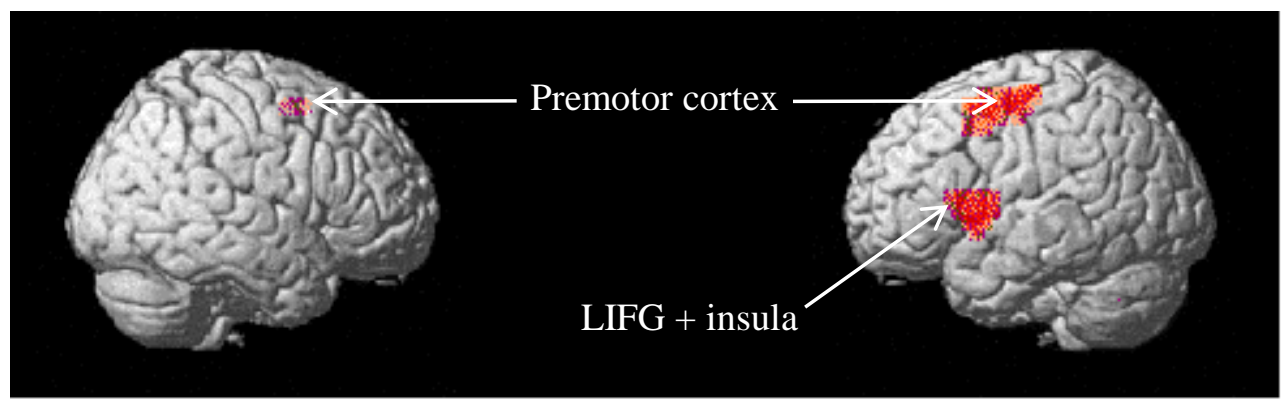




\section{FOOTNOTES}

${ }^{\mathrm{i}}$ In French as well as in English, agent deixis can be conveyed by syntax or by prosody (Berthoud, 1990). For instance, when conveying "Madeleine brought me around", one can specifically point at the agent "Madeleine" by using a deictic presentation form, either with the syntactic extraction "it's Madeleine who brought me around", or by producing an intonational contour bearing a focus on "Madeleine". See also Jackendoff (2002) for the use of stress and various syntactic constructions in conveying information structure - the partitioning of the message into presupposition vs. focus.

ii A high pitch accent is a local rising pitch movement which lends perceptual prominence. In French, when a constituent is prosodically focused, a pitch accent can be observed on one of the syllables of the constituent. This pitch-accented syllable is also usually longer. Inter-speaker variability may be observed in the syllable bearing the pitch prominence.

iii A grammatical transformation over a sentence involves the movement of a constituent from one position to another in the sentence. The position abandoned by the constituent is known as the "trace" [t], and is "bound" by that constituent (as in the transformation "The girl pushed the boy" $\rightarrow$ "The boy who the girl pushed [t]."). It is through the link between the trace and the constituent that thematic roles (agent, theme, goal, source, experiencer, etc.) are transmitted. 
iv According to some theories of syntax (Pollock, 1989), tense and agreement are located at distinct functional levels in the structure tree. 